\begin{tabular}{lcl}
\hline bentham open & The Open Materials Science Journal \\
CrossMark & Content list available at: www.benthamopen.com/TOMSJ/ \\
\hline
\end{tabular}

RESEARCH ARTICLE

\title{
Microwave-Assisted Synthesis of Pd Nanoparticles and Catalysis Application for Suzuki Coupling Reactions
}

\author{
Jian Zhang ${ }^{1}$ and Xuefeng Bai ${ }^{1,2, *}$ \\ ${ }^{I}$ School of Chemistry and Material Sciences, Heilongjiang University, Harbin 150080, China \\ ${ }^{2}$ Institute of Petrochemistry, Heilongjiang Academy of Sciences, Harbin 150040, China
}

Received: October 05,2016

Revised: December 22, 2016

Accepted: January 17, 2017

\begin{abstract}
A facile and efficient method was developed for the synthesis of highly active palladium nanoparticles (PdNPs) by microwave-assisted chemical reduction. The PdNPs with different morphology were prepared with or without $\mathrm{KBr}$ (capping agent) using ethylene glycol (EG) and citric acid (CA) as reducing agent in the presence of polyvinylpyrrolidone (PVP), respectively. The as-prepared PdNPs were characterized by (UV-Visible Spectrophotometer) UV-Vis, transmission electron microscopy (TEM) and Xray diffraction (XRD) analysis. The results showed that the PdNPs reduced by EG without KBr (PdNPs-EG) has smaller particle size than other PdNPs. The remarkable catalytic activity of the PdNPs catalysts are obtained using a low amount of PdNPs (0.1 mmol\%o) using $\mathrm{K}_{2} \mathrm{CO}_{3}$ as base and $\mathrm{EtOH} / \mathrm{H}_{2} \mathrm{O}$ as solvent toward Suzuki coupling reactions of aryl bromides and phenylboronic acid for 15 $\min$.
\end{abstract}

Keywords: Palladium nanoparticles, Microwave, Suzuki coupling reactions.

\section{INTRODUCTION}

The Suzuki coupling reactions catalyzed by the transition metal palladium are very powerful tools for the construction of C-C bonds since its discovery in 1979 [1]. It has been immensely applied to synthesize biphenyl compounds including natural products, agrochemicals, optical materials, and pharmaceuticals due to the mild reaction conditions and the broad functional group tolerance of this transformation [2 - 6].

The palladium-based catalysts are considered as the most available coupling catalysts, numerous efforts have been conducted to explore highly active catalytic systems [7]. The homogenous Pd catalysts with ligand generally exhibited higher catalytic activity and have been most frequently applied in Suzuki coupling reactions [8]. The ligand-free heterogeneous Pd catalysts via supporting Pd on organic polymers or inorganic solids [9 - 15] have also achieved much attention due to its recycling and reusing. Recently, Pd nanoparticles (PdNPs) with high surface-to-volume ratio and highly active surface atoms in comparison with those of the bulk catalysts exhibit excellent activity [16] and have attracted great interest. There are many factors such as nanoparticles size and shape that affect the catalytic activity of Pd nanoparticles. Therefore, numerous efforts have been made to develop effective and facile synthetic method to prepare well-defined and uniform-sized metal nanoparticles [17]. Microwave irradiation (MWI) methods provide simple and fast routes to the synthesis of nanomaterials without high temperature or high pressure. Moreover, the metal nanoparticles prepared by MWI have nanometer size with narrow size distribution [18 - 21].

In this paper, the microwave-assisted reduction method was employed to synthesize the PdNPs using CA and EG as reduction agent, respectively. The catalytic properties of the as-prepared PdNPs for the Suzuki coupling reactions were examined.

\footnotetext{
* Address correspondence to this author at the School of Chemistry and Material Sciences, Heilongiiang University, Harbin 150080; Institute of Petrochemistry, Heilongjiang Academy of Sciences, Harbin 150040, China; Tel: 13503609332; Fax: 86 45182623693; E-mails: 15146001506@163.com,tommybai@126.com
} 


\section{EXPERIMENTAL}

\subsection{Materials and Methods}

All chemical reagents used in this experiment including sodium chloride $(\mathrm{NaCl})$, palladium chloride $\left(\mathrm{PdCl}_{2}\right)$, Polyvinyl Pyrrolidone (PVP), ethanol, potassium bromide (KBr), ethylene glycol and citric acid (CA) were purchased from Tianjin Kermel and Sinopharm Chemical Reagent Co. Ltd. All chemicals were used as received and without further purification.

Transmission electron microscope (TEM) was performed on an FEI Tecnai G2 S-TWIN to obtain TEM images. The $\mathrm{X}$-ray diffraction (XRD) patterns were measured using a Bruker D8 advance diffractometer with a $\mathrm{Cu} \mathrm{K} \alpha(\lambda=0.15418$ $\mathrm{nm}$ ) radiation at $40 \mathrm{kV}$ and $40 \mathrm{~mA}$. UV-Vis spectrophotometers were obtained with a Shimadzu UV-2450, using a quartz cuvette as sample-holder.

\subsection{Preparation of PdNPs Reduced by Ethylene Glycol (EG)}

Add $10 \mathrm{ml}$ aqueous solution of PVP $(0.5 \mathrm{~mol} / \mathrm{L})$ to $10 \mathrm{ml}$ aqueous solution of $\mathrm{Na}_{2} \mathrm{PdCl}_{4}(0.05 \mathrm{~mol} / \mathrm{L})$ in a $50 \mathrm{ml}$ beaker and the solutions were stirred for $30 \mathrm{~min}$ followed by the addition of $2 \mathrm{ml}$ ethylene glycol and $8 \mathrm{ml}$ deionized water at room temperature. The mixture was then reduced by microwave irritation method at $85^{\circ} \mathrm{C}$ for a total reaction time of $90 \mathrm{~min}$ after the solutions were stirred for another $30 \mathrm{~min}$. After the reaction, a black stable suspension of $\mathrm{Pd}$ nanoparticles was obtained. The as-prepared PdNPs was denoted as PdNPs-EG. In addition, the PdNPs-KBr-EG was prepared following the same procedure mentioned above except for adding $0.2380 \mathrm{~g} \mathrm{KBr}$ to the solution of $\mathrm{Na}_{2} \mathrm{PdCl}_{4}$ and PVP.

\subsection{Preparation of PdNPs Reduced by Citric Acid (CA)}

The same procedure was used for the preparation of PdNPs except that the $10 \mathrm{ml}$ citric acid aqueous solution (0.2 $\mathrm{mol} / \mathrm{L}$ ) was slowly added as the reducing agent and the mixture was subjected to microwave irritation for $120 \mathrm{~min}$ at $90^{\circ} \mathrm{C}$. After the reaction, the obtained PdNPs was named as PdNPs-CA. The PdNPs-KBr-CA was also synthesized by dissolving $0.2380 \mathrm{~g} \mathrm{KBr}$ in the solution of $\mathrm{Na}_{2} \mathrm{PdCl}_{4}$ and PVP before adding citric acid.

\subsection{General Procedure for Suzuki Reactions}

Suzuki coupling reactions were conducted as follows: aryl halide $(1 \mathrm{mmol})$, phenylboronic acid $(1.5 \mathrm{mmol})$ and potassium carbonate $(2 \mathrm{mmol})$ were dissolved in a mixture solvent of $12 \mathrm{ml}$ ethanol:water $(\mathrm{v} / \mathrm{v}=1 / 1)$ and placed in a 30 $\mathrm{ml}$ microwave tube. The PdNPs were then added, and the tube was sealed and treated by microwave irradiation at $60^{\circ} \mathrm{C}$. The amount of PdNPs and reaction time were recorded in Table $\mathbf{1 .}$

Upon reaction completion, $5 \mathrm{ml}$ sodium hydroxide solution $(0.2 \mathrm{~mol} / \mathrm{L})$ was added to the reaction mixture $(5 \mathrm{ml})$, and the products were extracted with ethyl acetate $(10 \mathrm{ml})$. The organic layers were combined, dried in air to give a solid product. Analysis of the reaction products was carried out by the high performance liquid chromatography (HPLC) UltiMate 3000 using a mobile phase consisting of methanol and $\mathrm{H}_{2} \mathrm{O}(\mathrm{v} / \mathrm{v}=90: 10)$. Column temperature was set to $35^{\circ} \mathrm{C}$. UV-detection was performed at wavelengths of $254 \mathrm{~nm}$ over a run time of $15 \mathrm{~min}$.

\section{RESULTS AND DISCUSSION}

\subsection{Catalysts Characterization}

The formation of PdNPs-EG and PNPs-CA are monitored by UV-Vis spectrum, respectively. The progression of PNPs reduced by EG is shown in Fig. (1a). There is a strong characteristic peak around $420 \mathrm{~nm}$ in the spectrum in the absence of EG, which is attributed to Pd (II). It is obviously observed that the intense of Pd (II) peak gradually become weak after mixing with EG and treating by microwave irradiation at $85^{\circ} \mathrm{C}$. At the same time, the color of the mixture turns from yellow to black indicating the formation of PdNPs. The Pd (II) peak totally disappears after microwave irritation for $90 \mathrm{~min}$ indicating the complete reduction of $\mathrm{Pd}$ (II) in the mixture. From the Fig. (1b), the same phenomenon is found for the reduction process of PdNPs-CA except that the Pd (II) peak completely disappears after microwave irritation for $120 \mathrm{~min}$ at $90^{\circ} \mathrm{C}$. 
Table 1. The effect of base and solvent on the Suzuki coupling reaction ${ }^{\mathrm{a}}$.

\begin{tabular}{|c|c|c|c|c|c|c|}
\hline Entry & Base & Solvent & $\begin{array}{c}\text { Yield } \\
\mathbf{b} / \%\end{array}$ & $\begin{array}{c}\text { Yield } \\
\mathbf{c} / \%\end{array}$ & $\begin{array}{c}\text { Yield } \\
\mathbf{d} / \%\end{array}$ & $\begin{array}{c}\text { Yield } \\
\mathbf{c} / \%\end{array}$ \\
\hline 1 & $\mathrm{~K}_{2} \mathrm{CO}_{3}$ & $\mathrm{EtOH} / \mathrm{H}_{2} \mathrm{O}$ & 98.4 & 97.1 & 96.7 & 96.9 \\
\hline 2 & $\mathrm{~K}_{3} \mathrm{PO}_{4} \cdot 3 \mathrm{H}_{2} \mathrm{O}$ & $\mathrm{EtOH} / \mathrm{H}_{2} \mathrm{O}$ & 96.6 & 95.8 & 95.2 & 95.6 \\
\hline 3 & $\mathrm{NaOH}$ & $\mathrm{EtOH} / \mathrm{H}_{2} \mathrm{O}$ & 95.3 & 94.3 & 92.6 & 93.5 \\
\hline 4 & $\mathrm{NaOAc}$ & $\mathrm{EtOH} / \mathrm{H}_{2} \mathrm{O}$ & 95.1 & 93.7 & 91.8 & 94.0 \\
\hline 5 & $\mathrm{NEt}_{3}$ & $\mathrm{EtOH} / \mathrm{H}_{2} \mathrm{O}$ & 93.8 & 93.2 & 90.4 & 91.9 \\
\hline 6 & $\mathrm{~K}_{2} \mathrm{CO}_{3}$ & $\mathrm{MeOH} / \mathrm{H}_{2} \mathrm{O}$ & 96.9 & 95.9 & 95.2 & 95.7 \\
\hline 7 & $\mathrm{~K}_{2} \mathrm{CO}_{3}$ & $\mathrm{Toluene} / \mathrm{H}_{2} \mathrm{O}$ & 49.1 & 47.6 & 45.5 & 46.4 \\
\hline 8 & $\mathrm{~K}_{2} \mathrm{CO}_{3}$ & $\mathrm{CH}_{2} \mathrm{Cl} / \mathrm{H}_{2} \mathrm{O}$ & 58.4 & 55.7 & 53.8 & 54.9 \\
\hline 9 & $\mathrm{~K}_{2} \mathrm{CO}_{3}$ & $\mathrm{CH}_{3} \mathrm{CN} / \mathrm{H}_{2} \mathrm{O}$ & 50.5 & 49.5 & 46.6 & 47.1 \\
\hline 10 & $\mathrm{~K}_{2} \mathrm{CO}_{3}$ & $\mathrm{THF} / \mathrm{H}_{2} \mathrm{O}$ & 72.7 & 71.3 & 70.8 & 72.2 \\
\hline 11 & $\mathrm{~K}_{2} \mathrm{CO}_{3}$ & $\mathrm{DMF} / \mathrm{H}_{2} \mathrm{O}$ & 81.3 & 79.7 & 78.1 & 80.4 \\
\hline
\end{tabular}

${ }^{a}$ Reaction conditions: 4-bromotoluene $(1.0 \mathrm{mmol})$, phenylboronic acid $(1.5 \mathrm{mmol})$, PdNPs $(0.1 \mathrm{mmol} \%)$, base $(2.0 \mathrm{mmol})$, solvent $/ \mathrm{H}_{2} \mathrm{O}(6 \mathrm{~mL} / 6 \mathrm{~mL})$ for 15 min. ${ }^{b}$ PdNPs-EG ${ }^{c}$ PdNPs-KBr-EG ${ }^{d}$ PdNPs-CA ${ }^{e}$ PdNPs-KBr-CA.
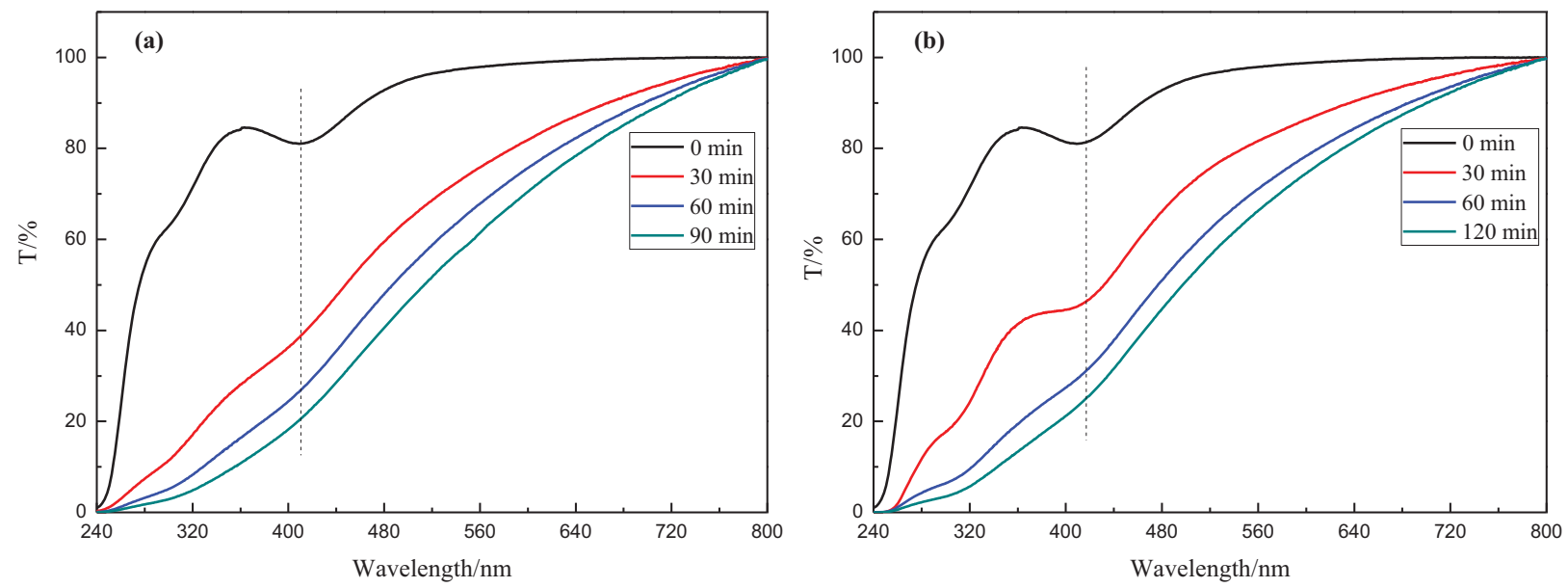

Fig. (1). UV-Vis spectrum of PdNPs: (a) PdNPs-EG; (b) PdNPs-CA.

The XRD patterns of the as-prepared PdNPs-EG, PdNPs-KBr-EG, PdNPs-CA and PdNPs-KBr-CA are shown in Fig. (2). Three main diffraction peaks with $2 \theta$ of $40.1^{\circ}, 46.6^{\circ}, 68.1^{\circ}$ are observed for all samples which are ascribed to Pd (111), Pd (200), Pd (220) phases, respectively, which match well with the standard face centered cubic (fcc) structure according to the JCPDS card no. 46-1043. For the PdNPs-KBr-EG, the peaks are stronger and narrower than those of the PdNPs-EG indicating the larger average particle size and higher crystallinity. Otherwise, the stronger and slight broader peaks are found in PdNPs-KBr-CA compared to the PdNPs-CA.

The TEM images and particles size distribution of as-prepared PdNPs are displayed in Fig. (3). From the images, the Pd nanoparticles with different morphology are all highly distributed in system indicating the microwave-assisted method can improve the dispersion of PdNPs in an aqueous phase. Figs. (3a and b) show the TEM images of the Pd nanoparticles reduced by EG with or without $\mathrm{KBr}$, respectively. TEM image Fig. (3a) shows the occurrence of highly dispersed spherical PdNPs with a narrow and homogeneous distribution. The particle size is range from 2.59-5.42 nm with an average diameter of $3.74 \mathrm{~nm}$. The rod-shaped PdNPs with a larger particle size between 3.25-9.78 nm (average diameter of $6.62 \mathrm{~nm}$ ) than PdNPs-EG are prepared in the presence of KBr. The TEM images of the Pd nanoparticles reduced by $\mathrm{CA}$ with or without $\mathrm{KBr}$ are presented in Figs. (3c and $\mathbf{d}$ ), respectively. The PdNPs-CA of different shape such as cube, tetrahedron and other polyhedron with an average diameter of $8.91 \mathrm{~nm}$ are found. TEM observation of PdNPs-KBr-CA shows a cubic and rodlike shape with an average particle size of $8.05 \mathrm{~nm}$ indicating an obvious different from the shape of PdNPs-CA, but a similar shape to PdNPs-KBr-EG. A possible reason for the change of PdNPs shapes is that bromide can absorb on the surface of PdNPs and change the order of surface free energies for 
different facets to promote the formation of different facets. Pd nanoparticles with cube and rod shape are easier to synthesize in the presence of $\mathrm{KBr}$.

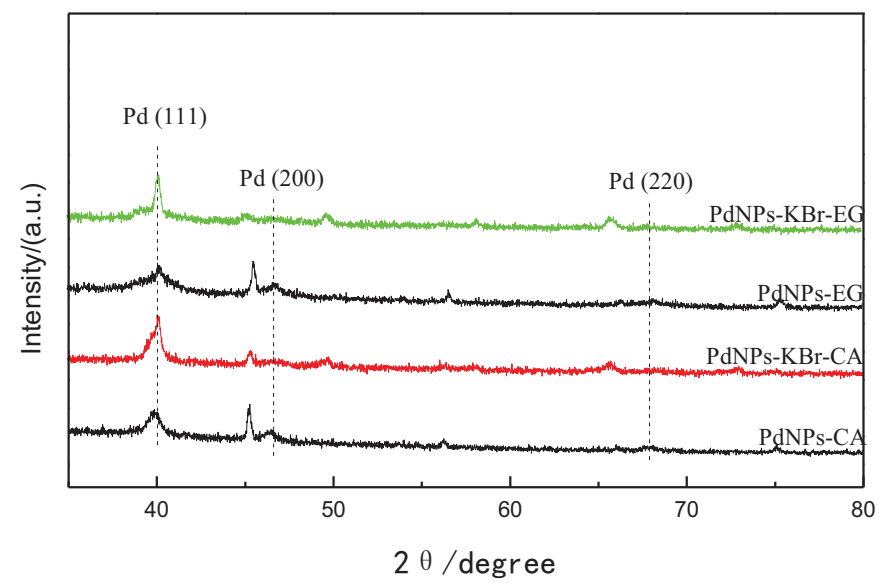

Fig. (2). XRD patterns of PdNPs-EG, PdNPs-KBr-EG, PdNPs-CA and PdNPs-KBr-CA.
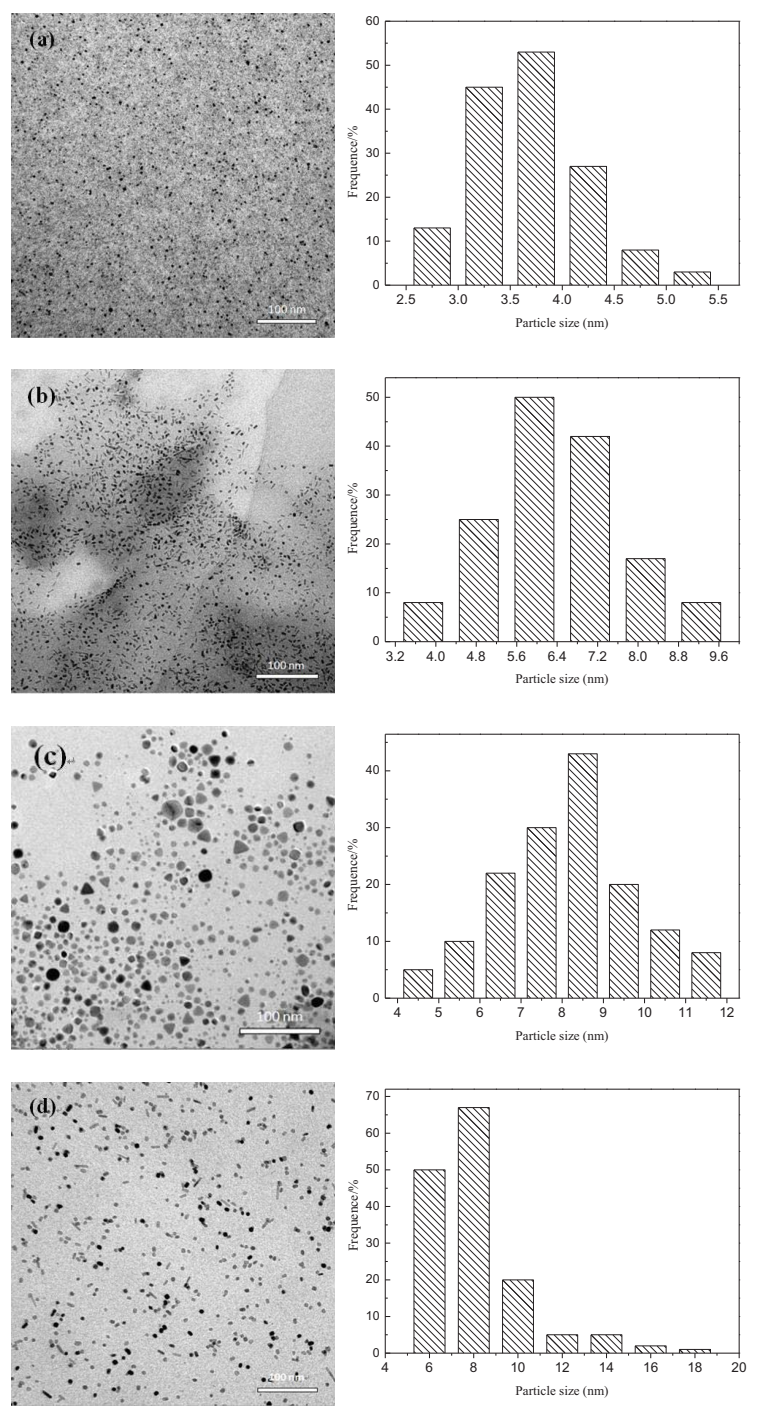

Fig. (3). TEM images and particle size distribution of PdNPs-EG, PdNPs-KBr-EG, PdNPs-CA and PdNPs-KBr-CA. 


\subsection{Catalytic Activity Toward Suzuki Reaction}

The catalytic activity of PdNPs-EG, PdNPs-KBr-EG, PdNPs-CA and PdNPs-KBr-CA were evaluated against the Suzuki coupling reaction by microwave irritation. We chose 4-bromotoluene and phenylboronic acid as a model reaction substrate (Scheme 1) to study the impact of various reaction conditions such as base and solvent on the reaction.<smiles>Cc1ccc(-c2cccc(C=[N+]=Nc3ccccc3)c2)cc1</smiles>

Scheme 1. PdNPs catalysts for Suzuki coupling reaction of 4-bromotoluene and phenylboronic acid.

The reaction was carried out using $0.1 \mathrm{mmol} \%$ PdNPs for $15 \mathrm{~min}$ to study the impact of different bases and solvents. The results are shown in Table 1. Of the various bases used, the bases, $\mathrm{K}_{3} \mathrm{PO}_{4} \cdot 3 \mathrm{H}_{2} \mathrm{O}, \mathrm{NaOH}, \mathrm{NaOAc}, \mathrm{NEt}_{3}$ achieve comparatively lower yields for all the PdNPs catalysts (>93\%), while $\mathrm{K}_{2} \mathrm{CO}_{3}$ gives the best result with $98.4 \%$, 97.1\%, 96.7\% and 96.9\% yields of the coupling product for PdNPs-EG, PdNPs-KBr-EG, PdNPs-CA and PdNPs-KBrCA, respectively. (Table 1, entries 1 vs 2-5).

Screening with different solvents shows that ethanol is a more effective solvent for this system; the solvent, $\mathrm{MeOH}$ gives slightly lower yields of $96.9 \%, 95.9 \%, 95.2 \%$ and $95.7 \%$ for PdNPs-EG, PdNPs-KBr-EG, PdNPs-CA and PdNPs$\mathrm{KBr}-\mathrm{CA}$, respectively (Table 1, entry 6). Poor yields of the product are obtained from other solvents (Table 1, entries 7-11). Adopting a green chemical approach, nontoxic ethanol is cheap and practical for use as a solvent for the synthesis.

To evaluate the catalytic ability of the prepared PdNPs catalysts, the Suzuki coupling reactions of phenylboronic acid and a diverse range of aryl halides were carried out using microwave irradiation. As illustrated in Table 2, the 4$\mathrm{OCH}_{3}, 4-\mathrm{NO}_{2}, 4-\mathrm{COCH}_{3}, 4-\mathrm{CN}$ and 4- $\mathrm{OCH}_{3}$ substituted aryl bromides obtain high yields of the corresponding product in the presence of $0.1 \mathrm{mmol} \%$ for $15 \mathrm{~min}$. For instance, the yield of $99.3 \%, 98.8 \%, 97.8 \%$ and $98.2 \%$ are obtained for the Suzuki coupling reaction of 4-bromoacetophenone with phenylboronic acid catalyzed by PdNPs-EG, PdNPs-KBrEG, PdNPs-CA and PdNPs-KBr-CA, respectively (Table 2, entry 4). However, because of the steric hindrance effect, the reactions of o-bromotoluene with phenylboronic acid provide a lower yield than the results for the reactions of $\mathrm{p}$ bromotoluene with phenylboronic acid under the same reaction conditions (Table 2, entries 2 vs 7). Especially for the obromoanisole, the poor yields (less than 50\%) are provided even though prolonging reaction time to 30 min (Table $\mathbf{2}$, entry 8). The Suzuki coupling reactions between phenylboronic acid and aryl chloride in the presence of $1 \mathrm{mmol} \%$ PdNPs were also investigated. As shown in Table 2, the very low yields are obtained under the current reaction conditions and a moderate yield is provided for the reaction of $\mathrm{p}$-chloroacetophenone with phenylboronic acid catalyzed by PdNPs-EG (Table 2, entries 9-11). Additionally, the moderate yields are obtained for the reactions of phenylboronic acid with heteroaryl bromide using $1 \mathrm{mmol} \%$ PdNPs (Table 2, entries 12-14). Considering the above results, the PdNPs-EG with smaller particle size and regular shape obtains a higher catalytic activity compared with PdNPs-KBrEG, PdNPs-CA and PdNPs-KBr-CA by comparing the yields for the same substrates under the same reaction conditions.

Table 2. Suzuki coupling reaction of various aryl halides with phenylboronic acid ${ }^{\text {. }}$

\begin{tabular}{|c|c|c|c|c|c|c|}
\hline Entry & Aryl halides & Time & $\begin{array}{c}\text { Yield } \\
\mathrm{b} / \%\end{array}$ & $\begin{array}{c}\text { Yield } \\
\mathrm{c} / \%\end{array}$ & $\begin{array}{c}\text { Yield } \\
\mathrm{d} / \%\end{array}$ & $\begin{array}{c}\text { Yield } \\
\mathrm{c} / \%\end{array}$ \\
\hline 1 & $\mathrm{Br}$ & $15 \mathrm{~min}$ & 94.3 & 93.5 & 90.3 & 92.4 \\
\hline 2 & $\mathrm{Br}$ & $15 \mathrm{~min}$ & 98.4 & 97.1 & 96.7 & 96.9 \\
\hline 3 & $\mathrm{Br}$ & $15 \mathrm{~min}$ & 96.3 & 96.0 & 89.4 & 93.5 \\
\hline
\end{tabular}




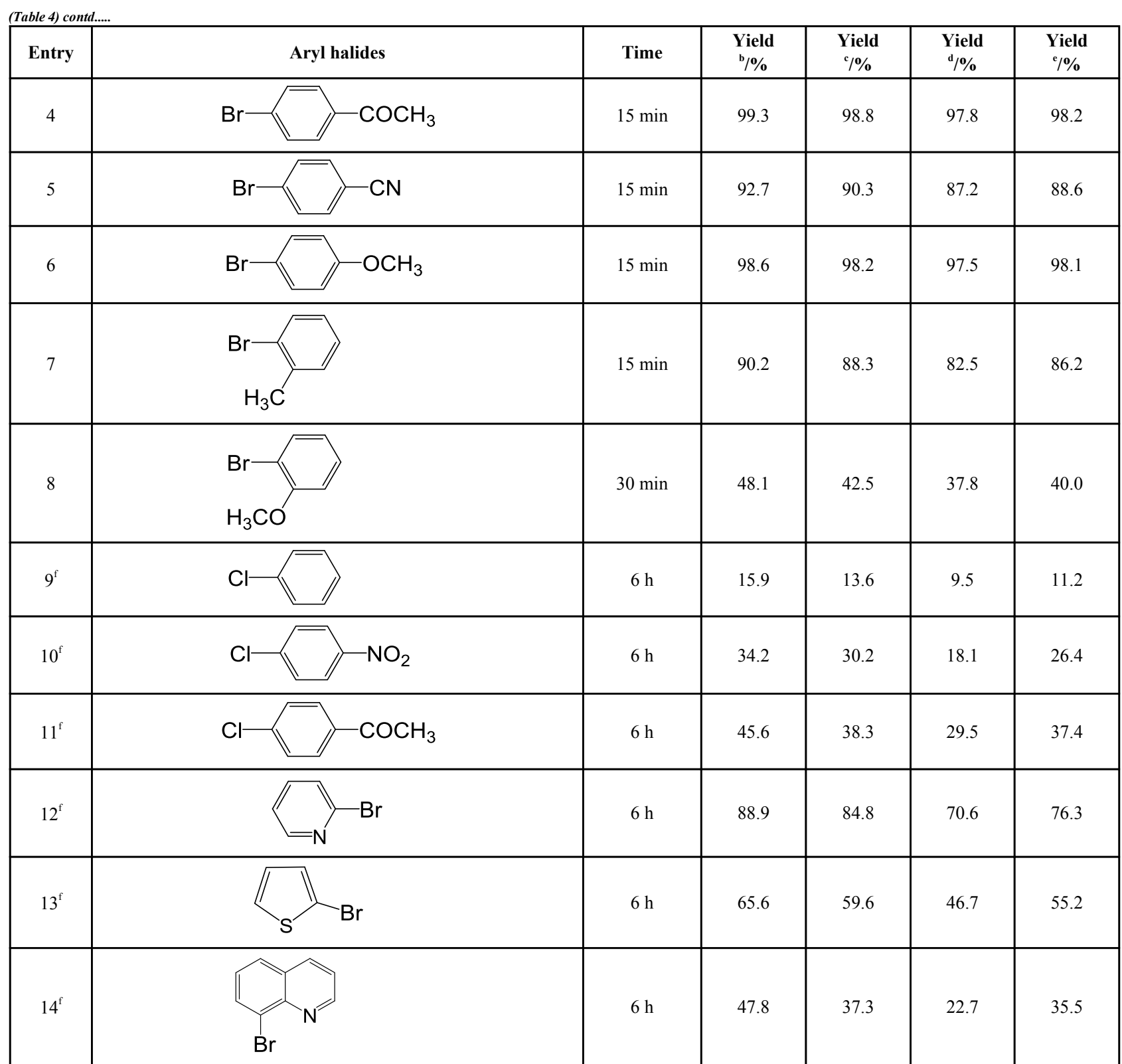

${ }^{a}$ Reaction conditions: aryl halide $(1 \mathrm{mmol})$, phenylboronic acid $(6 \mathrm{mmol}), \mathrm{K}_{2} \mathrm{CO}_{3}(2 \mathrm{mmol})$, PdNPs $(0.1 \mathrm{mmol} \%), \mathrm{EtOH} / \mathrm{H}_{2} \mathrm{O}(6 \mathrm{ml} / 6 \mathrm{ml}) .{ }^{\mathrm{b}} \mathrm{PdNPs}-$ EG ${ }^{\mathrm{c}}$ PdNPs-KBr-EG ${ }^{\mathrm{d}}$ PdNPs-CA ${ }^{\mathrm{e}}$ PdNPs-KBr-CA ${ }^{\mathrm{f}}$ PdNPs $(1 \mathrm{mmol} \%$ ).

\section{CONCLUSION}

In conclusion, the PdNPs with small particle size and high degree of dispersion protected by PVP have been prepared using ethylene glycol (EG) and citric acid (CA) as reducing agent, PVP as protecting agent by microwaveassisted chemical reduction. The Pd nanoparticles of special shape with an average diameter of $3.74 \mathrm{~nm}$ and heterogeneous shape with an average diameter of $6.62 \mathrm{~nm}$ are synthesized by EG and CA in the absence of $\mathrm{KBr}$, respectively. The PdNPs of cubic and rodlike shape are formed with $\mathrm{KBr}$ as a capping agent. The prepared PdNPs provided high yields in the Suzuki coupling reactions of various aryl bromides and phenylboronic acid using a low amount of PdNPs (0.1 mmol\%o) in a short reaction time. A 98.4\% yield is obtained for the Suzuki coupling reaction of 4-bromotoluene and phenylboronic acid catalyzed by PdNPs-EG. The 45.6\% and 88.9\% yields are obtained for Suzuki coupling reactions of phenylboronic acid with p-chloroacetophenone and 2-bromopyridine catalyzed by the PdNPs-EG at a low Pd loading (1mmol\%o) for $6 \mathrm{~h}$, respectively.

\section{CONFLICT OF INTEREST}

The authors confirm that this article content has no conflict of interest. 


\section{ACKNOWLEDGEMENTS}

This work was supported by the National Natural Science Foundation of China (Grant No.21276067), NSFC-RFBR (Grant No.214111301884), Program of International S\&T cooperation (Grant No.2013DFR40570) and Science Foundation of Heilongjiang Academy of Sciences.

\section{REFERENCES}

[1] Miyaura N, Suzuki A. Palladium-catalyzed cross-coupling reactions of organoboron compounds. Chem Rev 1995; 95: 2457-83. [http://dx.doi.org/10.1021/cr00039a007]

[2] Ronson TO, Taylor RJ, Fairlamb IJ. Palladium-catalysed macrocyclisations in the total synthesis of natural products. Tetrahedron 2015; 71: 989-1009.

[http://dx.doi.org/10.1016/j.tet.2014.11.009]

[3] Martin AD, Siamaki AR, Belecki K, Gupton BF. A convergent approach to the total synthesis of telmisartan via a Suzuki cross-coupling reaction between two functionalized benzimidazoles. J Org Chem 2015; 80(3): 1915-9. [http://dx.doi.org/10.1021/jo5025333] [PMID: 25522005]

[4] Liu YC, Qu RY, Chen Q, Wu QY, Yang GF. Efficient synthesis of functionalized 6-substituted-thiosalicylates via microwave-promoted Suzuki cross-coupling reaction. Tetrahedron 2014; 70: 2746-52. [http://dx.doi.org/10.1016/j.tet.2014.02.085]

[5] Wu WB, Huang LJ, Xiao L, et al. New second-order nonlinear optical (NLO) hyperbranched polymers containing isolation chromophore moieties derived from one-pot " $\mathrm{A}_{2}+\mathrm{B}_{4}$ ” approach via Suzuki coupling reaction. RSC Advances 2012; 2: 6520-6. [http://dx.doi.org/10.1039/c2ra20255g]

[6] Shim JY, Lee BH, Song S, et al. Synthesis and properties of the conjugated polymers with indenoindene and benzimidazole units for organic photovoltaics. J Polym Sci A Polym Chem 2013; 51: 241-9. [http://dx.doi.org/10.1002/pola.26385]

[7] Li H, Seechurn CC, Colacot TJ. Development of preformed Pd catalysts for cross-coupling reactions, beyond the 2010 Nobel Prize. ACS Catal 2012; 2: 1147-64.

[http://dx.doi.org/10.1021/cs300082f]

[8] Tang W, Patel ND, Xu G, et al. Efficient chiral monophosphorus ligands for asymmetric Suzuki-Miyaura coupling reactions. Org Lett 2012; 14(9): 2258-61.

[http://dx.doi.org/10.1021/ol300659d] [PMID: 22497425]

[9] Wang D, Liu W, Bian F. Magnetic polymer nanocomposite-supported Pd: an efficient and reusable catalyst for the Heck and Suzuki reactions in water. New J Chem 2015; 39: 2052-9. [http://dx.doi.org/10.1039/C4NJ01581A]

[10] Kurokhtina AA, Larina EV, Schmidt AF, et al. Mechanistic studies of the Suzuki-Miyaura reaction with aryl bromides using Pd supported on micro- and mesoporous activated carbons. J Mol Catal Chem 2013; 379: 327-32. [http://dx.doi.org/10.1016/j.molcata.2013.08.032]

[11] Siamaki AR, Lin Y, Woodberry K, Connell JW, Gupton BF. Palladium nanoparticles supported on carbon nanotubes from solventless preparations: versatile catalysts for ligand-free Suzuki cross coupling reactions. J Mater Chem A Mater Energy Sustain 2013; 1: $12909-18$. [http://dx.doi.org/10.1039/c3ta12512b]

[12] Speziali MG, Silva AG, Miranda DM, Monteiro AL, Robles-Dutenhefner PA. Air stable ligandless heterogeneous catalyst systems based on $\mathrm{Pd}$ and $\mathrm{Au}$ supported in $\mathrm{SiO}_{2}$ and MCM-41 for Suzuki-Miyaura cross-coupling in aqueous medium. Appl Catal A Gen 2013; 462-463: 39-45. [http://dx.doi.org/10.1016/j.apcata.2013.04.034]

[13] Kumbhar A, Kamble S, Mane A, Jha R, Salunkhe R. Modified zeolite immobilized palladium for ligand-free Suzuki-Miyaura cross-coupling reaction. J Organomet Chem 2013; 738: 29-34.

[http://dx.doi.org/10.1016/j.jorganchem.2013.03.031]

[14] Li SZ, Zhang W, So MH, Che CM, Wang R, Chen R. One-pot solvothermal synthesis of $\mathrm{Pd}_{\text {/ }} \mathrm{Fe}_{3} \mathrm{O}_{4}$ nanocomposite and its magnetically recyclable and efficient catalysis for Suzuki reactions. J Mol Catal Chem 2012; 359: 81-7. [http://dx.doi.org/10.1016/j.molcata.2012.03.025]

[15] Burrueco MI, Mora M, Jiménez-Sanchidrián C, Ruiz JR. Hydrotalcite-supported palladium nanoparticles as catalysts for the Suzuki reaction of aryl halides in water. Appl Catal A Gen 2014; 485: 196-201.

[http://dx.doi.org/10.1016/j.apcata.2014.07.031]

[16] Pérez-Lorenzo M. Palladium nanoparticles as efficient catalysts for Suzuki cross-coupling reactions. J Phys Chem Lett 2012; 3: 167-74. [http://dx.doi.org/10.1021/jz2013984]

[17] Wang X, Zhuang J, Peng Q, Li Y. A general strategy for nanocrystal synthesis. Nature 2005; 437(7055): 121-4. [http://dx.doi.org/10.1038/nature03968] [PMID: 16136139]

[18] Yang JH. Microwave-assisted synthesis graphite-supported Pd nanoparticles for detection of nitrite. Sens Actuators B Chem 2015; 220: $652-8$. 
[http://dx.doi.org/10.1016/j.snb.2015.05.118]

[19] Kainz QM, Linhardt R, Grass RN. Palladium nanoparticles supported on magnetic carbon-coated cobalt nanobeads: highly active and recyclable catalysts for alkene hydrogenation. Adv Funct Mater 2014; 24: 2020-7. [http://dx.doi.org/10.1002/adfm.201303277]

[20] Amin RS. Microwave heated synthesis of carbon supported Pd, Ni and Pd-Ninanoparticles for methanol oxidation in KOH solution. Appl Catal B 2014; 148-149: 557-67.

[http://dx.doi.org/10.1016/j.apcatb.2013.11.020]

[21] Lu X. Rapid, microwave-assisted, and one-pot synthesis of magnetic palladium- $\mathrm{CoFe}_{2} \mathrm{O}_{4}$-graphene composite nanosheets and their applications as recyclable catalysts. Part Syst Charact 2014; 31: 245-51. [http://dx.doi.org/10.1002/ppsc.201300216]

\section{(C) 2017 Zhang and Bai.}

This is an open access article distributed under the terms of the Creative Commons Attribution 4.0 International Public License (CC-BY 4.0), a copy of which is available at: (https://creativecommons.org/licenses/by/4.0/legalcode). This license permits unrestricted use, distribution, and reproduction in any medium, provided the original author and source are credited. 